\title{
Research on the Influence of Internet Technology on Traditional Sports Culture
}

\author{
Liangliang Sun \\ Sichuan University of Arts and Science, Dazhou, China \\ sunliang6@126.com
}

Keywords: Internet technology; Traditional sports culture; Influence; Research

\begin{abstract}
Our traditional sports culture has been greatly impacted with the rapidly development of Internet technology, it not only changes the traditional culture itself, but also affects people's attention to the traditional sports culture. By using the methods of documentation and logical analysis, this paper studies the influence of traditional sports culture under the internet technology. It is believed that the traditional culture is being dissolved because the Internet technology has disintegrated the living space of traditional sports, and the traditional sports culture under the Internet has gradually became a kind of cultural consumption and cultural products. Traditional sports culture in traditional space is father and father away from us. Finally, putting forward the corresponding thinking from the two sides of Internet technology under the development of traditional sports culture.
\end{abstract}

\section{Introduction}

Nowadays, the using of Internet technology in our daily life becomes more and more widely and it has penetrated into every aspect of our lives. Traditional sports culture is an important cultural content generated in our production and life. Today, it is also influenced by Internet technology. The following will analysis the brain of Internet technology reconstruction; the Internet technology disrupted the traditional sports living space; The space formed by Internet technology, and finally, discussing the development problem of traditional sports culture under the Internet technology.

\section{Analysis of Research Results}

\section{The Brain Reconstructed Under the Internet Technology}

It is different from the single direction propagation of TV and such electronic media, Internet technology is no longer limited to receiving information, but can respond to the information. Neman once said: we are witnessing a broad and intrinsically connected network development that includes the transmission of audio, video and electronic documents. "The use of technology strengthens some neural circuits and weakens others, making certain mental characteristics more prominent and making other characteristic areas disappear" ${ }^{[1]}$.The advent of several Internet technologies has profoundly influenced generations. The digital media represented by the Internet allows more faster and more diverse two-way transmission, and enhance the control of users. This has contributed to the remodeling of human brain stimulation and the formation of new neural circuits. The physical behavior of traditional sports cultural developing is a process of oral transmission and teaching by precept and example, it is a cultural transmission with the participation of physical practice. Under the network background, the transmission and inheritance of traditional culture is gradually weakened and then becomes the cultural transmission process of audio, video and electronic documentation. Finally, educating orally and in practice are replaced by mouse and keyboard, and the operation of the brain is completely different from the active participation of the body.

There's too much information and fragmented content in the internet resources. Numerous links affect people's view and various forms of information constantly attract our attention. What the brain in the internet need to constantly decide are whether to open the link, whether there're other links associated with it, what content is trustworthy, valuable and should be deleted, and so on, all 
of which require a coordination, evaluation and decision-making. The brain constantly transmit the information through constant judgment and switching, the process of thinking is interrupted in constant rebuilding. As a result, cognitive abilities become more and more difficult, and the brain is unable to rest at the situation of constant high speeds. It is supposed to be a process of understanding, explaining, remembering and learning the traditional sports culture. Under the intervention of the Internet, the brain gradually turns to judgment and pure "information decoding". The original concentrative, profound and rich nerve connection ability is gradually discarded. "When the real world disappeared, and the so called meaning disappeared" ${ }^{[2]}$,leaving behind a technical thinking, the screen world replaced the world of body practice.

The culture of physical behavior is faced with constant deconstruction and re-interpretation when traditional sports body behavior is marked as a "link" in the Internet. People's way of thinking in the recognizing and inheriting traditional sports culture has also changed dramatically, and the way of experiencing physical behavior has undergone profound changes too. The brain must respond differently to the way it receives and transmits traditional sports culture than before, because in the context of Internet intervention, "human nature has changes, ......He became a mass person" ${ }^{[3]}$.The nervous function of the masses gradually weakens or even disappears. The nervous circuits of "extensive reading" and "skimming" based on the Internet gradually form and jump in different links of the Internet makes it hard to maintain concentration and sustainability. The change from traditional sports to digital media on the Internet has not only changed the traditional sports culture itself ,but also affected the traditional life of the ethic group and the concentration of traditional culture. Tradition is facing been "extensive reading" and "skimming".

\section{Internet Technology Has Disrupted the Survival Space of Traditional Sports}

The emergence and popularization of digital media represented by the Internet has moved traditional social groups from physical distance to virtual space. This virtual space is a "place without space" made by means of technology. In this virtual space, people no longer have a common history, culture, identity and memory, but have a common interest orientation. The data codes, like the using of " 1 ", " 0 " constitute communication and interaction, and this kind of communication has little relevance with the traditional regional society. The group cohesion formed by the traditional sports culture during the traditional society has disappeared in the internet, and the Internet no longer has identity and common cultural memory.

The reason why Internet technology has disintegrated the survival space of traditional sports is because the Internet is driven by the market, people in the pursuit of interests in the process of operation in accordance with the principle of market, rather than starting from the principle of cultural commonality. The group in the Internet is seen as consumer instead of Internet citizen. Traditional sports culture under the Internet is not only positioned as a kind of cultural consumption and cultural products , but also the designing and producing in the process of consumption are mediocre so as to meet more people, occupying a larger Internet market and then obtain greater commercial interests ${ }^{[4]}$.

The digital media represented by the Internet has contributed to the world dominated by consumer culture. The whole digital world is rapidly becoming the forefront of consumer culture and many traditional sports culture has been involved in the digital wave. The virtual world created by the digital media provides various identities for the traditional sports culture, which can be disseminated in the information stream at will, and doesn't need to determine its authenticity. In fact, this traditional sports culture has changed its original cultural attributes, and is now just a consumed culture .People addicted to the Internet also become consumers of Internet "goods", and all they pursuit is just entertainment that consumption brings ${ }^{[5]}$.

\section{The Space Formed by Internet Technology}

The digital media technology represented by the Internet surpassed the electronic media and prompted the faster flow of information in space. The increasing speed of the Internet has made it possible for the faster flow of information. The traditional space-time is facing to be re-manufactured, the tradition in the compressed space-time is more easily across locations and ethic groups, and the final result is the integration of many traditional sports culture into the wave of 
globalization. The digital media represented by the Internet has become a tool for people to communicate with society and daily production in minority areas. Under the influence of the Internet digital media, there are more and more information which affected traditional sports culture .The link between information and human meaning will be cut off when information becomes an excess of garbage and can not solve the fundamental problems of the group, thus creating a difficult world to grasp. Our traditional sports culture is consuming itself in the information, the flooding, meaningless and losing control of information will eventually lead to the impact and disappearance of traditional sports culture and the profound connotation of traditional sports culture is bound to disappear, but many people have not realized this process.

Internet technology establishes a "virtual social space" which is different from the traditional society with information .People's interaction and communication in the "virtual social space" is no longer face-to-face communication and imparting. Traditional sports culture seems not so important because the Internet makes us away from the real world. The "sacredness" of traditional sports behavior has been broken by Internet technology and it's function of has been replaced by the function of the Internet, and the Internet can make people across time and places without responsibility. Internet technology is being accepted by more and more people in the traditional society. They get a vivid, dynamic and stimulating feeling in this "no margin" cyberspace, browsing in different websites with different identities, the traditional sports culture in the traditional space is father and father away from us.

\section{Thinking of Development}

Internet technology is a "double-edged sword". It will promote the spread, inheritance and development of traditional sports culture if it can be correctly guided and standardized. Specially speaking, first of all, we can provide strong technical support for the protection, opening and dissemination of traditional sports culture by means of Internet media, establishing database and digital museum. The attention and mastery of the traditional sports culture of the netizens can be enhanced by virtue of the advantages and convenience of the Internet so as to promote the exchange and dissemination of traditional sports culture.

Secondly, the Internet has broken the traditional social space but also brought a revolution for the heritage of traditional sports culture. In the past, traditional sports culture learning was handed down on the spot, but now it can not meet the requirements of people's learning. People can browse and study on the Internet anytime, anywhere through Internet technology. Of course, it also requires people who master traditional sports culture to actively participate in the Internet traditional sports culture tradition, in order to establish a traditional sports dissemination learning platform.

Thirdly, Internet communication is an important means to establish the image of traditional sports culture. As an important part of group culture, many forms of sports culture show people's kindness, courage and strength. There're many national memories and a lot of outlook on life, world outlook and values in traditional sports culture, which becoming a good symbol of the group. How to spread the traditional sports culture to the outside by means of the Internet has very important value for the inheritance of excellent traditional culture.

\section{Reference}

[1] Nicholas Carr. How the Internet poisoned our brains [M]. Translated by Liu Chunyi. Beijing: CITIC Press, 2010:52.

[2] Dong Lu. The journey of variation: Tracing the source of contemporary cultural crisis [M]. Beijing: Kyushu press, 2016:84.

[3] Neal Boltzmann. The Disappearance of Childhood [M].Translated by Wu Yanting . Beijing: CITIC publishing house, 2017:52.

[4] Jiang Yuanlun. Media culture and consumption era[M]. Beijing: Central Compilation and Translation Press, 2004:135-140. 
[5] Yi Jian Dong. Sports culture [M]. Beijing: Beijing Sport University press, 2009. 